\title{
Use of carvedilol in hypertension: an update
}

\author{
This article was published in the following Dove Press journal: \\ Vascular Health and Risk Management \\ 16 May 2012 \\ Number of times this article has been viewed
}

\author{
Gastone Leonetti' \\ Colin G Egan ${ }^{2}$ \\ 'Istituto Auxologico Italiano, Ospedale \\ San Luca, Milan, Italy; ${ }^{2}$ Primula \\ Multimedia SRL, Pisa, Italy
}

\begin{abstract}
: $\beta$-blockers are effective antihypertensive agents and, together with diuretics, have been the cornerstone of pioneering studies showing their benefits on cardiovascular morbidity and mortality as a consequence of blood pressure reduction in patients with hypertension. However, evidence from recent meta-analyses have demonstrated no benefit afforded by atenolol compared with placebo in risk of mortality, myocardial infarction, or stroke, and a higher risk of mortality and stroke with atenolol/propranolol compared with other antihypertensive drug classes. Thus, the effect of these agents on cardiovascular morbidity and mortality in hypertensive patients, especially their use in uncomplicated hypertension, has remained largely controversial. However, it is recognized that the clinical studies used in these meta-analyses were mainly based on the older second-generation $\beta$-blockers, such as atenolol and metoprolol. Actually, considerable heterogeneity in, eg, pharmacokinetic, pharmacological, and physicochemical properties exists across the different classes of $\beta$-blockers, particularly between the second-generation and newer third-generation agents. Carvedilol is a vasodilating noncardioselective third-generation $\beta$-blocker, without the negative hemodynamic and metabolic effects of traditional $\beta$-blockers, which can be used as a cardioprotective agent. Compared with conventional $\beta$-blockers, carvedilol maintains cardiac output, has a reduced prolonged effect on heart rate, and reduces blood pressure by decreasing vascular resistance. Studies have also shown that carvedilol exhibits favorable effects on metabolic parameters, eg, glycemic control, insulin sensitivity, and lipid metabolism, suggesting that it could be considered in the treatment of patients with metabolic syndrome or diabetes. The present report provides an overview of the main clinical studies concerning carvedilol administered as either monotherapy or in combination with another antihypertensive or more frequently a diuretic agent, with particular focus on the additional benefits beyond blood pressure reduction.
\end{abstract}

Keywords: carvedilol, $\beta$-blocker, hypertension, diabetes, atherosclerosis

\section{Introduction}

Arterial hypertension is a major risk factor for stroke, coronary events, and renal failure. ${ }^{1-3}$ Current estimates suggest that over 70 million adults in the United States and approximately one billion adults worldwide have hypertension. ${ }^{4,5}$ These poor figures can be attributed to undetected hypertensive patients (blood pressure [BP] never previously measured), known but untreated hypertension, and known hypertensive patients with low adherence to both antihypertensive drug therapies and lifestyle recommendations. ${ }^{4,6}$

Due to the need to obtain BP normalcy, guidelines published by the European Society of Hypertension/European Society of Cardiology recommend initiation of
Correspondence: Colin G Egan Primula Multimedia SRL, Via G Ravizza 22/b, Ospedaletto, Pisa, 56121, Italy Tel +39050965 6242

$\mathrm{Fax}+390503163810$

Email cegan@primulaedizioni.it 
monotherapy in patients with baseline first-degree arterial hypertension, mild/moderate global cardiovascular risk, or a target $\mathrm{BP}<140 / 90 \mathrm{mmHg}$, while combination therapy is suggested in patients with baseline second-degree or more arterial hypertension, high or very high global cardiovascular risk, or a target $\mathrm{BP}<130 / 80 \mathrm{mmHg}$. Combination therapy is particularly recommended when monotherapy fails to reach BP goals or in patients at high global cardiovascular risk..$^{1-3}$

For the past four decades, $\beta$-blockers have been used to treat hypertension. ${ }^{7,8}$ These agents have been shown to reduce cardiovascular-related mortality in clinical trials, and following these observations, both the European Society of Hypertension/European Society of Cardiology and JNC-7 guidelines recommend use of $\beta$-blockers as first-line or second-line antihypertensive agents. ${ }^{1-3}$

However, in recent years the use of $\beta$-blockers (especially for uncomplicated hypertension) has been controversial and widely debated. ${ }^{9-12}$ This has been mainly due to the findings from meta-analyses and clinical trials demonstrating a lack of benefit from $\beta$-blockers compared with placebo or other antihypertensive agents. ${ }^{13-19}$ Following this, the National Institute for Health and Clinical Excellence hypertension guidelines in the UK downgraded the use of $\beta$-blockers from first-line agents for hypertension to fourth-line add-on therapy. ${ }^{20,21}$ More recent National Institute for Health and Clinical Excellence guidelines state that $\beta$-blockers are not a preferred initial therapy for hypertension, but may be considered in younger people, particularly those with an intolerance or contraindication to angiotensin-converting enzyme inhibitors and angiotensin II receptor blockers, women of child-bearing potential, and people with evidence of increased sympathetic drive. ${ }^{22}$

Although conclusions drawn from these meta-analyses and later incorporated into the hypertension guidelines appear to cast $\beta$-blockers in a poor light, it needs to be pointed out that there were some limitations in these studies that may in part account for the poor effects observed. Atenolol was used in many of these studies as a once-daily dose, whereas ideally it should be taken more frequently, based on its pharmacokinetic properties. ${ }^{23}$ In addition, the majority of trials included elderly patients, who are recognized to be not as responsive to $\beta$-blockers as younger patients. ${ }^{24}$ However, the major critical weakness lies in the fact that most of the studies included older "traditional" agents (eg, propranolol and atenolol) that have no vasodilatory effects. This observation is extremely important, given that $\beta$-blockers are not a homogeneous class and exert markedly different effects according to their individual physicochemical and pharmacological characteristics. ${ }^{20}$

In fact, current JNC-7 guidelines recommend use of $\beta$-blockers for the initial treatment of patients with stage 1 hypertension and compelling indications, eg, previous myocardial infarction, ischemic heart disease, heart failure, diabetes, or high risk of coronary artery disease. ${ }^{1}$ Furthermore, $\beta$-blockers are also recommended for initial treatment in patients with stage 1 hypertension without compelling indications and in patients with stage 2 hypertension who require a combination of drugs to achieve BP control. ${ }^{1}$

Third-generation vasodilating $\beta$-blockers such as celiprolol, carvedilol, and nebivolol, do not possess some of the unfavorable effects often associated with other $\beta$-blocker compounds. ${ }^{3}$ These newer drugs reduce BP as well if not better than other antihypertensive agents. ${ }^{25,26} \mathrm{It}$ is also recognized that vasodilating $\beta$-blockers have a favorable metabolic and tolerability profile compared with older traditional $\beta$-blockers. ${ }^{7,27,28}$ Furthermore, both carvedilol and nebivolol have been used in outcome studies of chronic heart failure and were shown to reduce the primary endpoint of mortality and hospitalization..$^{29}$

With regard to carvedilol, the antihypertensive and ancillary benefits conferred by this vasodilating $\beta$-blocker are worth highlighting. Compared with other antihypertensive drugs, carvedilol has been shown to achieve superior or comparable $\mathrm{BP}$ reduction in hypertensive patients, whether administered as monotherapy $(25 \mathrm{mg} / \text { day })^{25,26,30}$ or in combination with another antihypertensive agent, such as a diuretic. ${ }^{31,32}$ Additional benefits afforded by carvedilol include: its use in specific hypertensive patients at risk of coronary artery disease, where it has been shown to increase coronary flow reserve; ${ }^{33,34}$ the postmyocardial infarction setting, where carvedilol is indicated; ${ }^{35}$ and in patients with diabetes or metabolic syndrome, in whom carvedilol has favorable metabolic characteristics ${ }^{36}$ in addition to providing renal protection. ${ }^{37,38}$ This review article summarizes the main findings from clinical studies examining the pharmacologic and metabolic properties of carvedilol in hypertension and concomitant diseases.

\section{Mode of action}

Carvedilol is a racemic mixture of ( \pm )-1-(carbazol-4yloxy)-3-[[2-(o-methoxyphenoxy) ethyl]amino]-2-propanol (Figure 1). It is a lipophilic vasodilating noncardioselective $\beta$-blocker which lacks intrinsic sympathomimetic activity, thus having improved tolerability compared with older $\beta$-blockers. ${ }^{28,39}$ Carvedilol is absorbed rapidly following oral administration and is extensively metabolized in the liver. ${ }^{40}$ The older generation "traditional" $\beta$-blockers selectively 


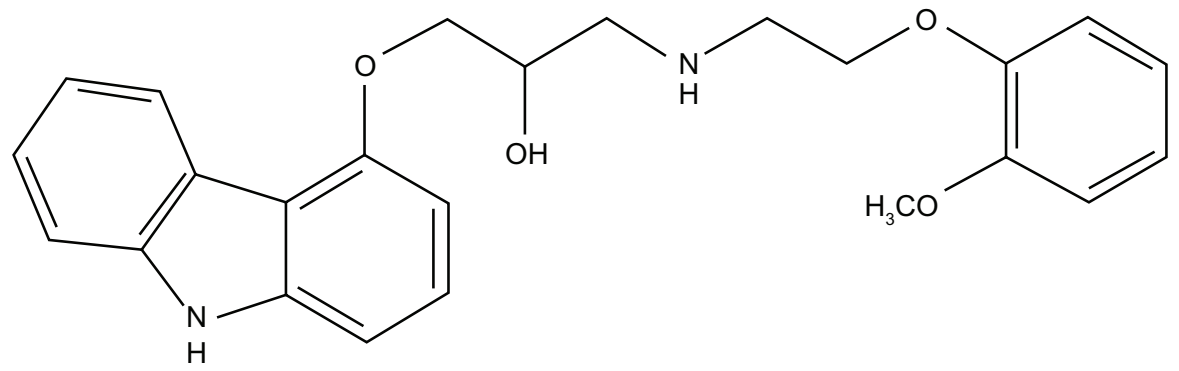

Figure I Chemical structure of carvedilol.

antagonize $\beta 1$-adrenergic receptors or antagonize both $\beta 1$-adrenergic and $\beta 2$-adrenergic receptors. ${ }^{41}$ They also reduce BP mainly through a reduction in cardiac output, while systemic vascular resistance remains largely unchanged. ${ }^{9}$ In contrast, carvedilol blocks norepinephrine binding to $\alpha 1$-adrenergic receptors in addition to both $\beta 1$-adrenergic and $\beta 2$-adrenergic receptors. ${ }^{28,39,42}$ This results in a reduction in arterial BP by maintaining cardiac output and decreasing total $\beta$-adrenoreceptor vasoconstrictor tone. ${ }^{9,43}$ Therefore, as can be seen in Table 1, the hemodynamic effect exerted by carvedilol is similar to that of angiotensin-converting enzyme inhibitors and markedly superior to that of traditional $\beta$-blockers.

In addition to its BP-reducing effects, carvedilol also has a superior metabolic profile in terms of lipid and glucose metabolism compared with traditional $\beta$-blockers ${ }^{44}$ (Table 1 ). This specific effect is addressed in further detail later in this review. In addition, carvedilol also exerts antioxidant effects attributable to stimulation of nitric oxide production, as well as having anti-inflammatory effects. ${ }^{39,45,46}$

\section{BP-lowering as monotherapy}

Regardless of the drug employed, monotherapy allows achievement of BP target values in a limited number of hypertensive patients. ${ }^{2,3}$ Carvedilol is indicated for the treatment of essential hypertension. It can be administered alone or in combination with other antihypertensives, particularly with a thiazide diuretic.

Early studies have shown that single administration of carvedilol $25-50 \mathrm{mg}$ results in a consistent reduction in BP over 24 hours compared with placebo, confirming its activity throughout daily activity and sleeping periods. ${ }^{47,48}$ Approximately $90 \%$ of the peak reduction in BP is observed at the time of the next dose.

In addition, clinical studies have shown that carvedilol $25 \mathrm{mg}$ once daily decreases arterial BP to a greater extent than the traditional $\beta$-blocker, atenolol, in patients with moderate and essential hypertension, respectively. ${ }^{49,50}$

Furthermore, comparative studies have also shown that carvedilol reduces BP to a similar extent as other antihypertensive drugs in patients with essential hypertension. A review by Moser et al reported data from three different studies with carvedilol compared with captopril, an angiotensin-converting enzyme inhibitor, slow-release nifedipine, a long-acting calcium channel blocker, and hydrochlorothiazide, a diuretic. ${ }^{51}$ The extent of BP reduction with carvedilol was similar to that achieved by comparator drugs (Figure 2A).

Table I Effects of different antihypertensive drugs in hypertensive patients

\begin{tabular}{llllllll}
\hline Parameter & $\begin{array}{l}\text { Ideal } \\
\text { drug }\end{array}$ & $\begin{array}{l}\text { ACEI } \\
\text { or ARB }\end{array}$ & Carvedilol & $\begin{array}{l}\alpha \text { I-adrenoceptor } \\
\text { blocker }\end{array}$ & $\begin{array}{l}\text { DHP calcium } \\
\text { antagonist }\end{array}$ & $\begin{array}{l}\text { Traditional } \\
\beta \text {-blockers }\end{array}$ & $\begin{array}{l}\text { Thiazide } \\
\text { diuretic }\end{array}$ \\
\hline MAP & $\downarrow$ & $\downarrow$ & $\downarrow$ & $\downarrow$ & $\downarrow$ & $\downarrow$ & $\downarrow$ \\
TPR & $\downarrow$ & $\downarrow$ & $(\downarrow)$ & $\downarrow$ & $\downarrow$ & $(\uparrow)$ & $(\downarrow)$ \\
Cardiac output & 0 & 0 & 0 & 0 & $(\uparrow)$ & $\downarrow$ \\
Heart rate & $0 / \downarrow$ & 0 & $\downarrow$ & $(\uparrow)$ & $\uparrow$ & $\downarrow$ \\
SNS activation & $\downarrow$ & $\downarrow$ & $\downarrow$ & $(\uparrow)$ & 0 & $\downarrow$ \\
RAS & $\downarrow$ & $\downarrow$ & $\downarrow$ & 0 & 0 & - \\
Lipid metabolism & $0 /+$ & $0 /+$ & 0 & $0 /+$ & 0 & - \\
Glucose metabolism & $0 /+$ & 0 & 0 & 0 & -
\end{tabular}

Notes: Effects are color-coded where white represents positive effect whereas black represents negative effects and light grey and dark grey represent slight positive and slight negative effects respectively. Data drawn from Messerli FH, Grossman E. Beta-blockers in hypertension: is carvedilol different? Am J Cardiol. 2004;93 Suppl:7B-I2B. ${ }^{9}$ Abbreviations: ACEI, angiotensin-converting enzyme inhibitor; ARB, angiotensin receptor blocker; DHP, dihydropyridine; MAP, mean arterial blood pressure; SNS, sympathetic nervous system; RAS, renin-angiotensin system; TPR, total peripheral resistance; $\uparrow$, increase (activation); $\downarrow$, decrease (inhibition); 0 , no effect; +, positive effect; -, negative effect; ( ), predominantly after acute administration. 
Systolic blood pressure

$\square$ Diastolic blood pressure

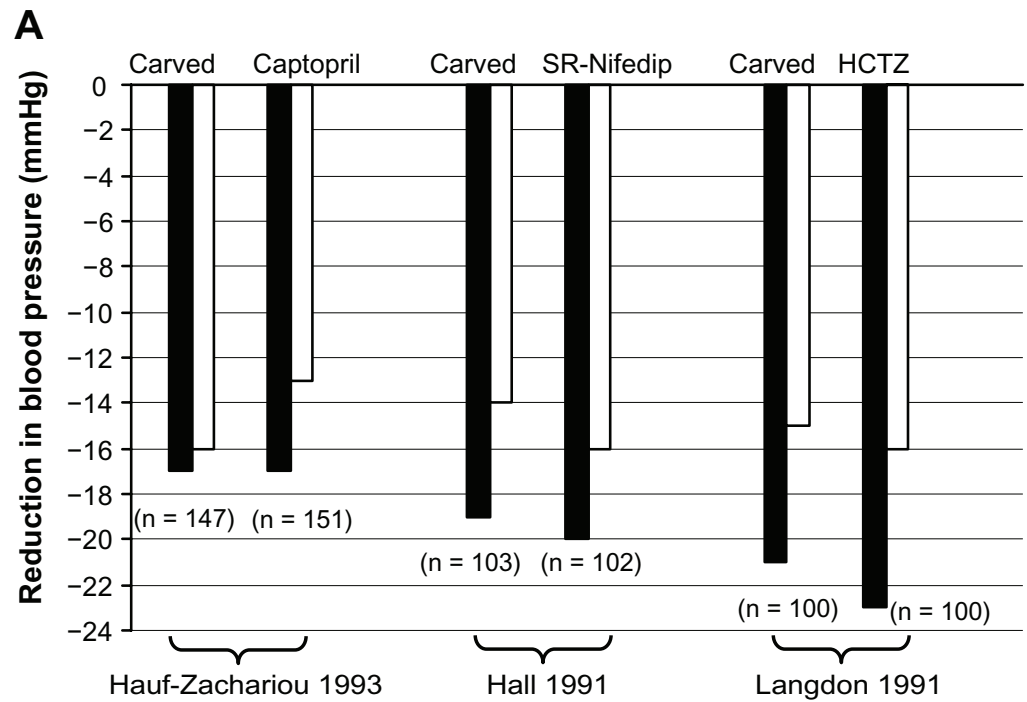

B

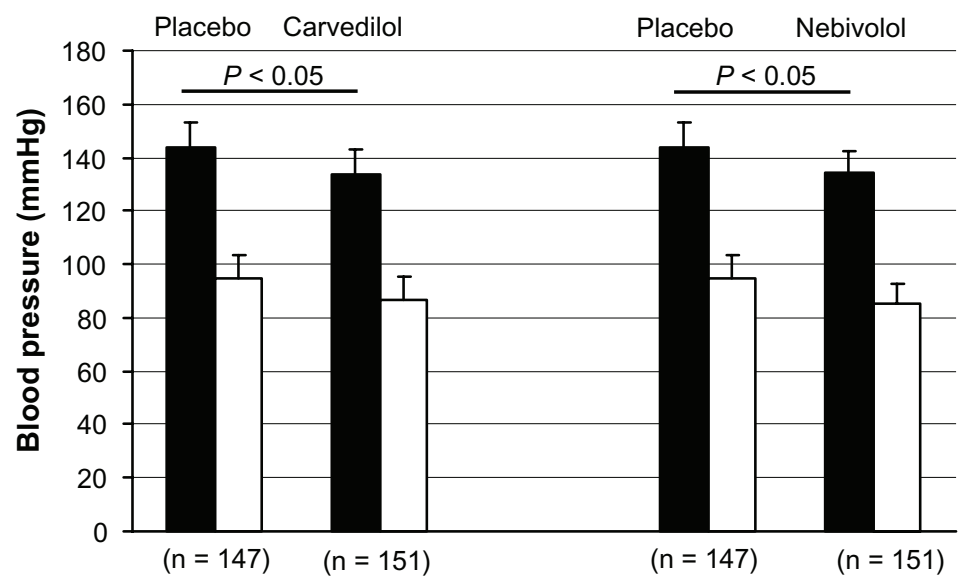

Figure 2 Antihypertensive effect of carvedilol compared with captopril, slow-release nifedipine, hydrochlorothiazide, and nebivolol. (A) Carvedilol was administered at 25-50 mg once daily. Captopril was administered at $25-50 \mathrm{mg}$ twice daily. Slow-release nifedipine was administered at $20-40$ mg twice daily and hydrochlorothiazide was administered at 25-50 mg once daily. Reprinted by permission from Macmillan Publishers Ltd: American Journal of Hypertension. Moser M, Frishman W. Results of therapy with carvedilol, a beta-blocker vasodilator with antioxidant properties, in hypertensive patients. Am J Hypertens. 1998; I (I Pt 2):15S-22S. Copyright I998.51 (B) Antihypertensive effect of carvedilol $5 \mathrm{mg} /$ day versus nebivolol $5 \mathrm{mg} /$ day. Copyright (c) 201 I, Aves Yayincilik. Adapted with permission from Erdoğan O, Ertem B, Altun A. Comparison of antihypertensive efficacy of carvedilol and nebivolol in mild-to-moderate primary hypertension: a randomized trial. Anadolu Kardiyol Derg. 20I I; I I (4):3 I0-3। 3. Turkish. ${ }^{30}$

Notes: $P$ values represent significant differences compared with placebo (for either carvedilol or nebivolol) for mean systolic and diastolic blood pressure. Filled bars represent systolic blood pressure and open bars represent diastolic blood pressure.

Abbreviations: SR-Nifedip, slow-release nifedipine; Carved, carvedilol; HCTZ, hydrochlorothiazide.

In addition, a more recent clinical trial examined the antihypertensive effect of carvedilol $25-50 \mathrm{mg} /$ day compared with another calcium channel blocker, amlodipine, at $5-10 \mathrm{mg}$ /day in patients with mild-to-moderate hypertension. ${ }^{26}$ Both drugs reduced systolic and diastolic BP in a dosedependent manner, and although amlodipine reduced systolic $\mathrm{BP}$ to a greater extent, the reduction in diastolic BP was similar for both agents. These findings suggest that carvedilol can be considered as an alternative option for the treatment of mild-to-moderate hypertension. Although carvedilol has a clearcut advantage over traditional $\beta$-blockers in terms of
$\mathrm{BP}$ reduction, these hemodynamic effects also rival those of nebivolol, another third-generation vasodilatory $\beta$-blocker. The antihypertensive effect was examined between carvedilol $25 \mathrm{mg} /$ day and nebivolol $5 \mathrm{mg}$ /day in patients with mild-tomoderate hypertension. ${ }^{30}$ Patients experienced a significant reduction in both systolic and diastolic BP on carvedilol or nebivolol compared with placebo $(P<0.05$, Figure $2 \mathrm{~B})$. No significant difference was observed in the extent of BP reduction between carvedilol and nebivolol (Figure 2B). Collectively, these clinical studies show that once-daily administration of carvedilol $25 \mathrm{mg}$ as monotherapy provides 
a reduction in BP that is equivalent to, if not better than, other antihypertensive agents.

\section{BP-lowering in combination therapy}

Although it can now be seen that carvedilol is an effective antihypertensive agent when administered as monotherapy, it is most frequently administered in combination with another antihypertensive agent, such as a diuretic. In fact, both the European and JNC-7 guidelines recommend combination therapy, especially when monotherapy fails to reach BP goals or in patients at high cardiovascular risk. ${ }^{1-3}$

Over 20 years ago, a small double-blind comparative trial conducted in 126 patients with mild-to-moderate hypertension showed that long-term administration of carvedilol $25 \mathrm{mg}$ /day decreased BP to a greater extent than atenolol $50 \mathrm{mg} /$ day. However, a combination of either of these drugs with hydrochlorothiazide produced an additive and equivalent response. ${ }^{31}$ This additive effect was also observed to a similar extent by the same authors in different patients $(n=122)$, this time pretreated with hydrochlorothiazide $25 \mathrm{mg}$ for 4 weeks and then given atenolol $50 \mathrm{mg} /$ day or carvedilol $25 \mathrm{mg} /$ day. ${ }^{49}$ Both carvedilol and atenolol were safe when given alone or in combination with hydrochlorothiazide.

This additive effect was also observed in other studies. A single-blind single-center study examined the shortterm efficacy and safety of adding carvedilol $25 \mathrm{mg}$ /day to hydrochlorothiazide $25 \mathrm{mg}$ /day in patients inadequately treated with hydrochlorothiazide alone. ${ }^{52}$ After 7 days of combined treatment, $53 \%$ of patients achieved diastolic BP levels $<90 \mathrm{mmHg}$ and $93 \%$ of patients achieved BP levels $<95 \mathrm{mmHg}$. Furthermore, another clinical trial has investigated the antihypertensive effect of the carvedilolhydrochlorothiazide combination in 26 severely hypertensive patients. ${ }^{53}$ Initially patients were inadequately treated with hydrochlorothiazide (diastolic BP > $120 \mathrm{mmHg}$ ); however, after 8 weeks of daily administration of carvedilol $(10 \mathrm{mg}$ or $20 \mathrm{mg}$ ) on an outpatient basis, both systolic and diastolic BP were significantly decreased ( $P<0.001$ for both). No patient experienced bradycardia, and carvedilol was generally well tolerated.

Overall, these studies demonstrate that carvedilol $10-25 \mathrm{mg}$ once daily in combination with hydrochlorothiazide is an effective and safe therapeutic option for patients with mild-to-moderate or severe hypertension. In addition to hydrochlorothiazide, the BP-lowering effect of carvedilol has also been examined in combination with the third-generation vasodilatory $\beta$-blocker, nebivolol. ${ }^{54}$ This retrospective study examined the effect of atenolol 50-100 mg/day, a carvedilolnebivolol combination $(25+25 \mathrm{mg} /$ day and $5 \mathrm{mg} /$ day, respectively) and patients chronically treated with angiotensin II receptor blockers. ${ }^{54}$ The findings of this study revealed that patients treated with angiotensin II receptor blockers or the carvedilol-nebivolol combination were associated with lower central systolic BP than atenolol treatment, suggesting that, like angiotensin II receptor blockers, vasodilating $\beta$-blockers can exert more favorable central hemodynamic effects than atenolol.

\section{Effects on lipid metabolism}

Previous studies have shown that traditional $\beta$-blockers can have detrimental effects on serum lipids, including increasing triglycerides and decreasing high-density lipoprotein levels. ${ }^{9,55-58}$ Carvedilol, on the other hand, has been shown to have a neutral or beneficial effect on lipoprotein lipase activity and levels of triglycerides and high-density lipoprotein cholesterol ${ }^{9,59}$ (Figure 3).

These favorable effects on lipid metabolism were confirmed later in the GEMINI (Glycemic Effects in Diabetes Mellitus: Carvedilol-Metoprolol Comparison in Hypertensives $)$ trial, a large $(\mathrm{n}=1235)$ randomized, double-blind comparison of the effect of carvedilol versus metoprolol in hypertensive diabetic patients. This study showed that patients treated with carvedilol had decreased low-density lipoprotein cholesterol, but not with metoprolol, and triglyceride levels were not increased, as with metoprolol. ${ }^{36,60}$

Another comparative randomized trial examined the effect of once-daily extended-release carvedilol or extended-release metoprolol in hypertensive patients without diabetes and not requiring lipid-lowering therapy. ${ }^{61}$ Although there was no difference in the effect of the two drugs on high-density lipoprotein or BP, triglyceride levels were increased by metoprolol but not by carvedilol. This differential metabolic profile could be important in determining treatment options in this patient group.

A recent review article examined 12 published studies and case reports that evaluated the impact of carvedilol on lipid profile. ${ }^{62}$ Although it was clear that $\beta 1$-selective antagonists worsen the lipid profile compared with carvedilol, it remained unclear as to whether carvedilol independently improves or has a neutral effect on lipid profile. Regardless, carvedilol should still be considered a favorable choice for the treatment of patients with heart failure and/or hypertension with dyslipidemia.

\section{Effects in diabetes}

It is well recognized that conventional $\beta$-blockers exert negative effects on glucose control and insulin sensitivity, while also increasing the risk of new-onset diabetes in hypertensive 

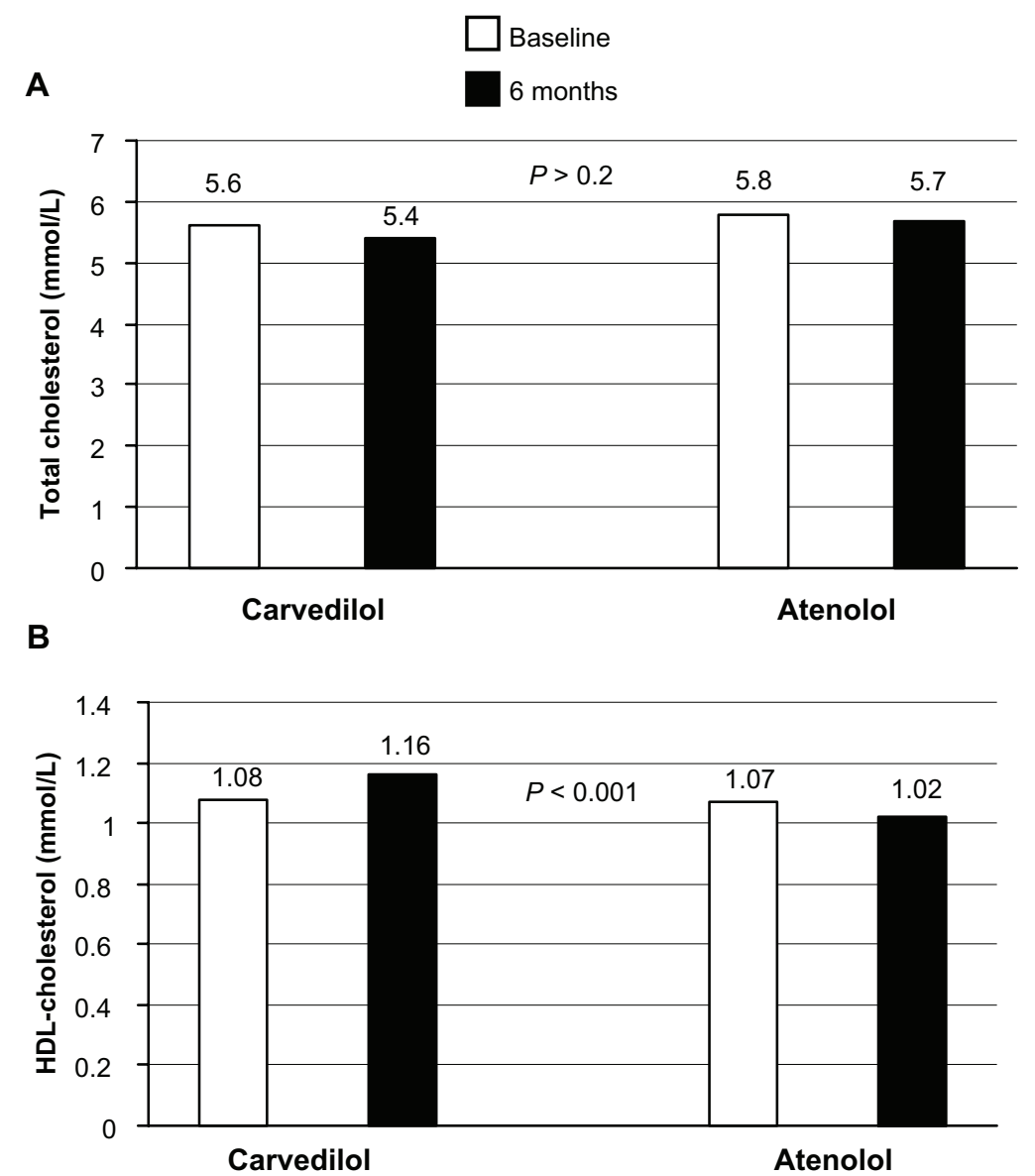

C

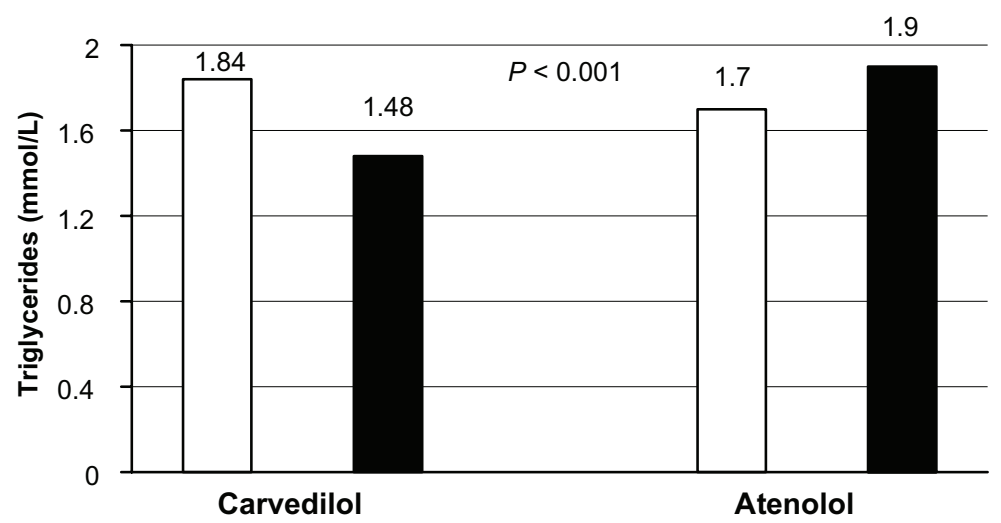

Figure 3 Comparison of the effects of carvedilol and atenolol on lipid parameters in patients with hypertension. P values represent significant differences in HDL cholesterol (B) and triglycerides (C) between carvedilol and atenolol treatment; the difference for total cholesterol was not significant (A). Open bars represent baseline and filled bars represent the 6-month time point.

Notes: Data values are also presented. Carvedilol was administered at $25 \mathrm{mg}$ once daily $(\mathrm{n}=23)$ and atenolol was administered at $50 \mathrm{mg}$ once daily ( $\mathrm{n}=22)$. Copyright (c) I997, American College of Physicians-American Society of Internal Medicine. Adapted with permission from Giugliano D, Acampora R, Marfella R, et al. Metabolic and cardiovascular effects of carvedilol and atenolol in non-insulin-dependent diabetes mellitus and hypertension. A randomized, controlled trial. Ann Intern Med. I997:I26(I2):955-959.59 Abbreviation: HDL, high-density lipoprotein.

patients. ${ }^{9,18,63}$ However, earlier studies with $\beta$-blockers having vasodilatory properties have shown beneficial effects on glycemic control and insulin sensitivity. ${ }^{64,65}$ More recently, the effects of carvedilol and atenolol were examined in hypertensive patients with type 2 diabetes. This study demonstrated that after 24 weeks of treatment, fasting plasma glucose and glycosylated hemoglobin $\left(\mathrm{HbA}_{1 \mathrm{c}}\right)$ were decreased and insulin sensitivity was increased with carvedilol, whereas atenolol had the opposite results ${ }^{59}$ (Figure 4).

Furthermore, in COMET (Carvedilol or Metoprolol European Trial), the risk for new-onset diabetes was $22 \%$ lower in patients receiving carvedilol than those receiving 

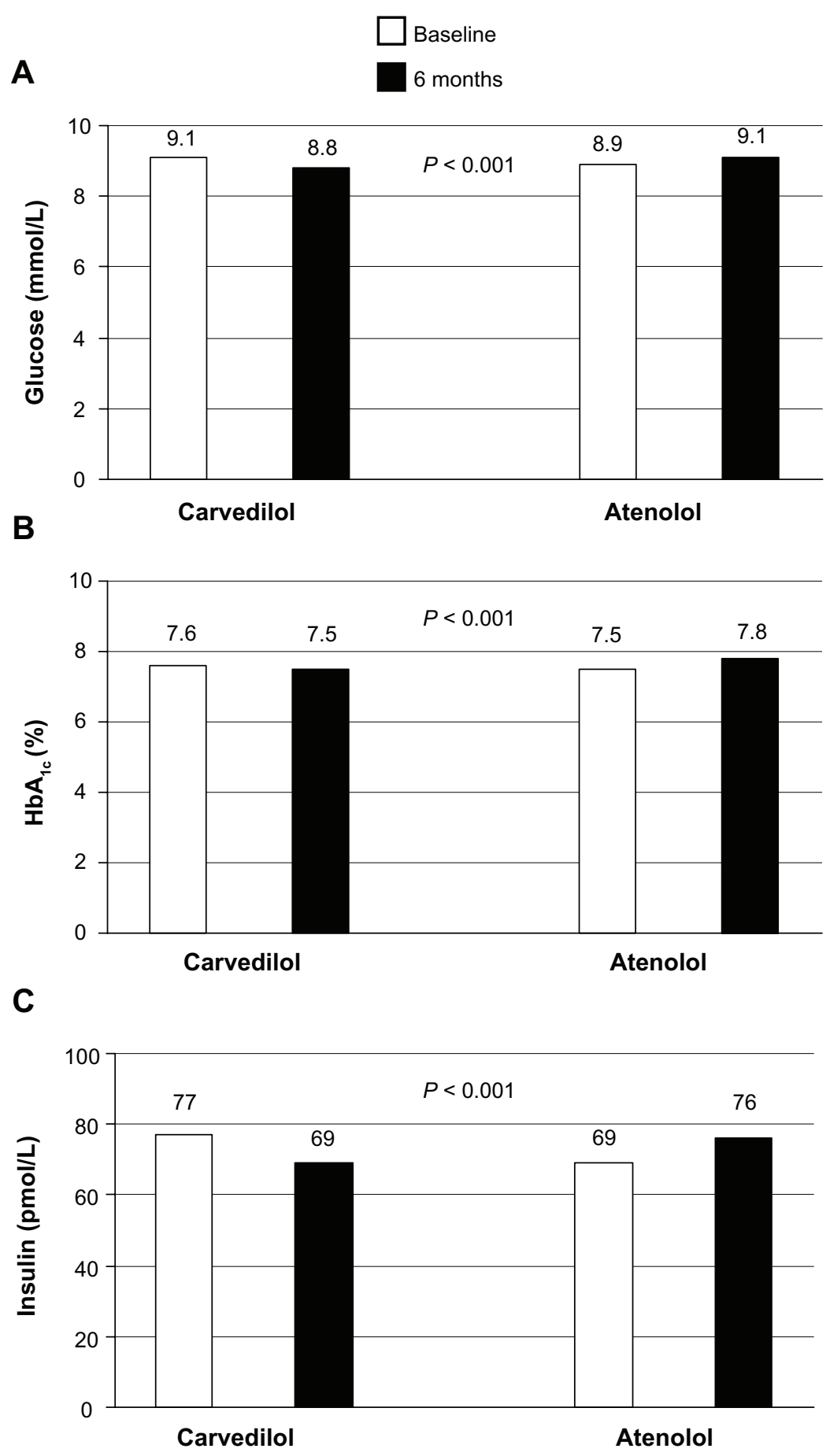

Figure 4 Comparison of the effects of carvedilol and atenolol on metabolic parameters in patients with hypertension. $P$ values represent significant differences in metabolic parameters $(\mathbf{A}-\mathbf{C})$ between carvedilol and atenolol treatment. Open bars represent baseline and filled bars represent the 6-month time point.

Notes: Data values are also presented. Carvedilol was administered at $25 \mathrm{mg}$ once daily $(\mathrm{n}=23)$ and atenolol was administered at $50 \mathrm{mg}$ once daily $(\mathrm{n}=22)$. Copyright (c) I997, American College of Physicians-American Society of Internal Medicine. Adapted with permission from Giugliano D, Acampora R, Marfella R, et al. Metabolic and cardiovascular effects of carvedilol and atenolol in non-insulin-dependent diabetes mellitus and hypertension. A randomized, controlled trial. Ann Intern Med. 1997:I26(I2):955-959.59 Abbreviation: $\mathrm{HbA}_{1 \mathrm{c}}$, glycosylated hemoglobin.

metoprolol. ${ }^{66}$ The effects of carvedilol were next examined in a large comparative trial in patients with type 2 diabetes. In the GEMINI trial, the effect of carvedilol treatment was compared with metoprolol in 1235 patients with hypertension and type 2 diabetes. ${ }^{36,67}$ At the end of the study, carvedilol lowered systolic and diastolic BP to the same extent as metoprolol. ${ }^{36}$ However, the discontinuation rate because of poor glycemic control was $2.2 \%$ with metoprolol but only $0.6 \%$ with carvedilol $(P<0.04)$. Furthermore, carvedilol had no adverse effect on $\mathrm{HbA}_{\mathrm{lc}}$ values. ${ }^{67}$ While nonvasodilating $\beta$-blockers are often associated 
with undesirable effects on insulin sensitivity and masking of symptoms of hypoglycemia in this patient population, findings from the GEMINI study suggest that carvedilol does not share these negative effects. It is also worth noting that the progression to microalbuminuria was less frequent with carvedilol than with metoprolol (6.4\% versus $10.3 \%$; odds ratio $0.60 ; 95 \%$ confidence interval: $0.36-0.97 ; P=0.04)$. This difference may be due to an improvement in insulin resistance or to an effect on oxidant stress by carvedilol. ${ }^{59}$

Many of these earlier comparative studies were included (from the period of 1980-2008) in a recent schematic review that examined the effect of both nonvasodilating and vasodilating $\beta$-blockers (including carvedilol) on glucose, metabolic, and lipid parameters. ${ }^{27}$ The main findings from this analysis demonstrated that vasodilatory $\beta$-blockers were associated with more favorable effects on glucose and lipid profiles than nonvasodilating $\beta$-blockers.

More recently, a clinical trial has examined the effect of metoprolol versus carvedilol on endothelial function and insulin-stimulated endothelial function in patients with type 2 diabetes. ${ }^{44}$ Insulin-stimulated endothelial function deteriorated after treatment with metoprolol, whereas there was no change with carvedilol. This study demonstrated that vascular insulin sensitivity was preserved in diabetic patients treated with carvedilol but blunted during treatment with metoprolol. ${ }^{44}$

\section{Effects in metabolic syndrome}

In addition to diabetic patients, carvedilol is also recognized to have beneficial effects in patients with metabolic syndrome. ${ }^{68} \mathrm{~A}$ recent randomized comparative study examined the effect of carvedilol versus atenolol or doxazosin for 3 months in 77 patients with metabolic syndrome. ${ }^{69}$ At the end of the study period, a similar reduction in both systolic and diastolic BP was observed for all three treatment groups. Furthermore, no significant differences were observed between the three groups for a range of biochemical parameters, including plasma glucose, uric acid, urea, cholesterol (total and low-density lipoprotein), triglycerides, apoproteins, insulin, $\mathrm{HbA}_{1 \mathrm{c}}$, and homeostasis model assessment-insulin resistance (HOMA-IR). However, only carvedilol did not alter low-density lipoprotein levels (percent change for doxazosin $-5.6 \pm 13.5$ and atenolol $-8 \pm 9.8$ versus carvedilol $-0.1 \pm 12.2$, respectively; $P<0.05) .{ }^{69}$ Furthermore, these favorable effects of carvedilol were observed on other parameters (in addition to reduction in BP) that identify the metabolic syndrome, such as reduction in waist circumference, body mass index, and fasting blood glucose (Figure 5). It is worth noting that the effects of atenolol on insulin sensitivity may be attributed, in part, to the lower insulin levels and higher $\mathrm{HbA}_{1 \mathrm{c}}$ levels in this group than in the other treatment groups. ${ }^{69}$ Furthermore, differences in the glucose-lowering and insulin-lowering effects of atenolol between the studies by Giugliano et al (Figure 4) and Uzunlulu et al (Figure 5) may be due to the aforementioned differences in baseline insulin and $\mathrm{HbA}_{1 \mathrm{c}}$ levels, as well as the additional counseling on diet and exercise received by these patients. ${ }^{59,69}$

Although renin-angiotensin system inhibitors are recommended for the management of hypertensive patients with metabolic syndrome, head-to-head trials examining these

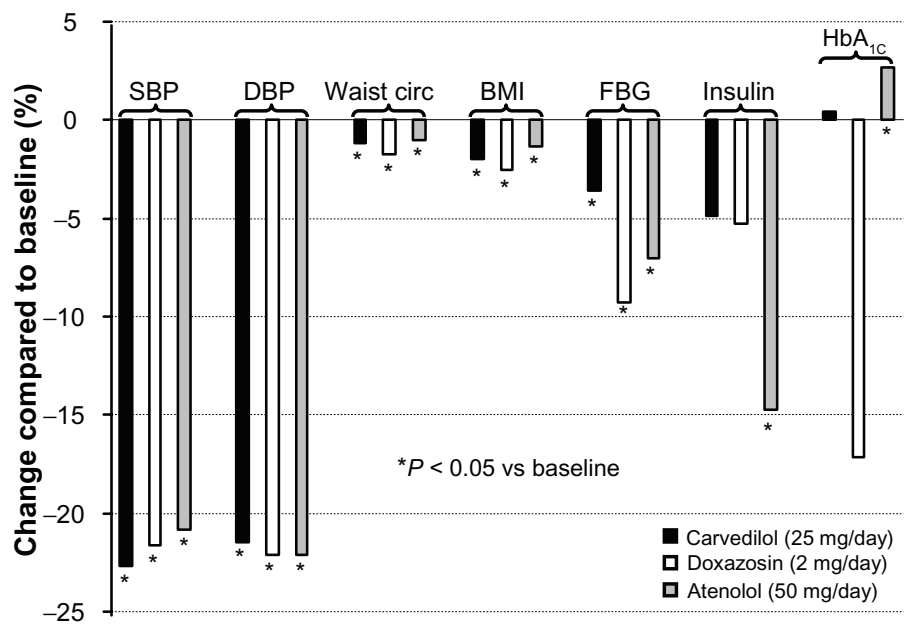

Figure 5 Effects of different antihypertensive drugs on metabolic parameters in patients with metabolic syndrome.

Note: *Significant difference $(P<0.05)$ versus baseline values. Copyright (c) 2006 , International Heart Journal Association. Adapted with permission from Uzunlulu M, Oguz A, Yorulmaz E. The effect of carvedilol on metabolic parameters in patients with metabolic syndrome. Int Heart J. 2006;47(3):42I-430.69

Abbreviations: SBP, systolic blood pressure; DBP, diastolic blood pressure; waist circ, waist circumference; BMI, body mass index; FBG, fasting blood glucose; HbA ${ }_{1 \mathrm{c}}$ glycosylated hemoglobin. 
agents against carvedilol are lacking. Overall, the evidence underscores the benefits of carvedilol and suggests that this drug should be considered as a promising therapeutic option in hypertensive patients with metabolic syndrome.

\section{Effect on left-ventricular hypertrophy}

Development of left-ventricular hypertrophy (LVH) in hypertensive patients is associated with an increased risk of cardiovascular mortality and morbidity. ${ }^{70}$ Although there is evidence that the older traditional $\beta$-blockers are not as effective at reducing $\mathrm{LVH}$ as other drug classes, ${ }^{71,72}$ these early studies did not examine vasodilatory $\beta$-blockers like carvedilol or nebivolol. Therefore, it is plausible that the $\alpha$-blocking effect of carvedilol may provide superior benefit in terms of LVH regression, compared with traditional $\beta$-blockers. In fact, there are several preclinical and clinical studies available to suggest that carvedilol may be effective in the regression of $\mathrm{LVH}^{.7-75}$ In particular, the study by Verza et al examined the effect of 6 months of daily therapy with carvedilol $25 \mathrm{mg}$ on LVH in elderly patients (mean age 69 years) with essential hypertension and LVH. ${ }^{74}$ Carvedilol caused a significant reduction in systolic and diastolic BP (Figure 6A) and LVH, as measured by left ventricular mass in addition to left ventricular mass index (Figure 6B).

In addition, a clinical trial evaluated the independent and combined effects of captopril and carvedilol on left ventricular remodeling in chronic heart failure in 57 patients. $^{76}$ Although angiotensin-converting enzyme inhibitor therapy did not alter left ventricular volume, treatment with carvedilol was associated with a reduction in chamber volume. Both drugs reduced left ventricular mass and sphericity. These beneficial effects on remodeling may help explain the relative prognostic benefits of these therapies.

\section{Effect on coronary flow reserve}

It is recognized that patients with LVH have lower coronary flow reserve, and there is evidence demonstrating that carvedilol can increase coronary flow reserve in these patients. ${ }^{33,77}$ A study performed in 63 hypertensive patients with LVH showed that carvedilol, but not metoprolol, increased coronary flow reserve in addition to decreasing left-ventricular mass index ${ }^{33}$ (Figure 7A).

Further, three clinical studies clearly confirm the beneficial effect of carvedilol therapy for 1-6 months on coronary flow reserve (Figure 7B), ${ }^{78-80}$ the magnitude of this benefit (absolute increase in coronary flow reserve) being greater than in three studies that examined the effect of nebivolol

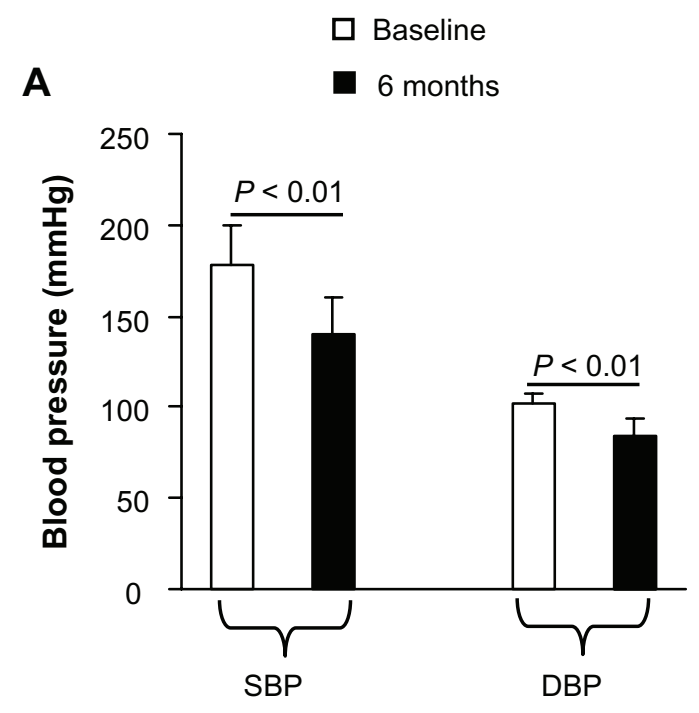

B

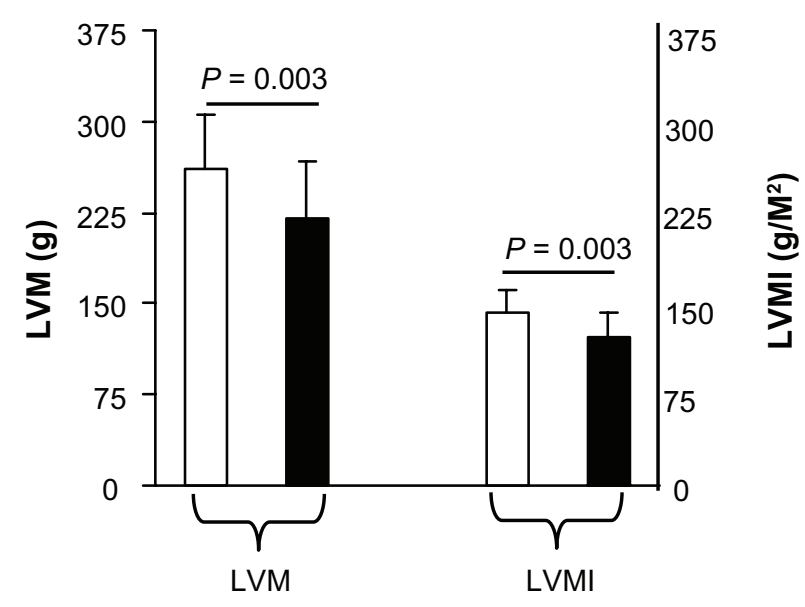

Figure 6 Effect of carvedilol on left ventricular hypertrophy in hypertensive patients. Notes: Carvedilol was administered at $25 \mathrm{mg}$ once daily $(\mathrm{n}=22)$. Data are presented as the mean \pm standard deviation. Reprinted from Archives of Gerontology and Geriatrics, 22 Suppl I, Verza M, Ammendola S, Cambardella A, et al, Regression of left ventricular hypertrophy in hypertensive elderly patients with carvedilol, 143-147, Copyright 1996, with permission from Elsevier. ${ }^{74}$

Abbreviations: SBP, systolic blood pressure; DBP, diastolic blood pressure; LVM, left ventricular mass; LVMI, left ventricular mass index.

on coronary flow reserve (Figure 7C). ${ }^{81-83}$ This improvement in coronary blood flow strongly suggests the use of vasodilating $\beta$-blockers, such as carvedilol, in patients at risk of atherosclerosis or coronary artery disease. ${ }^{34}$

\section{Following myocardial infarction}

Previous trials have shown benefit in patients receiving $\beta$-blocker therapy following myocardial infarction. ${ }^{35,84-87}$ The American Heart Association guidelines recommend that patients without a clear contraindication to $\beta$-blocker therapy should receive $\beta$-blockers within a few days of myocardial infarction and continue them indefinitely. ${ }^{88,89}$ Likewise, both the JNC-7 and European Society of Hypertension/European 
A

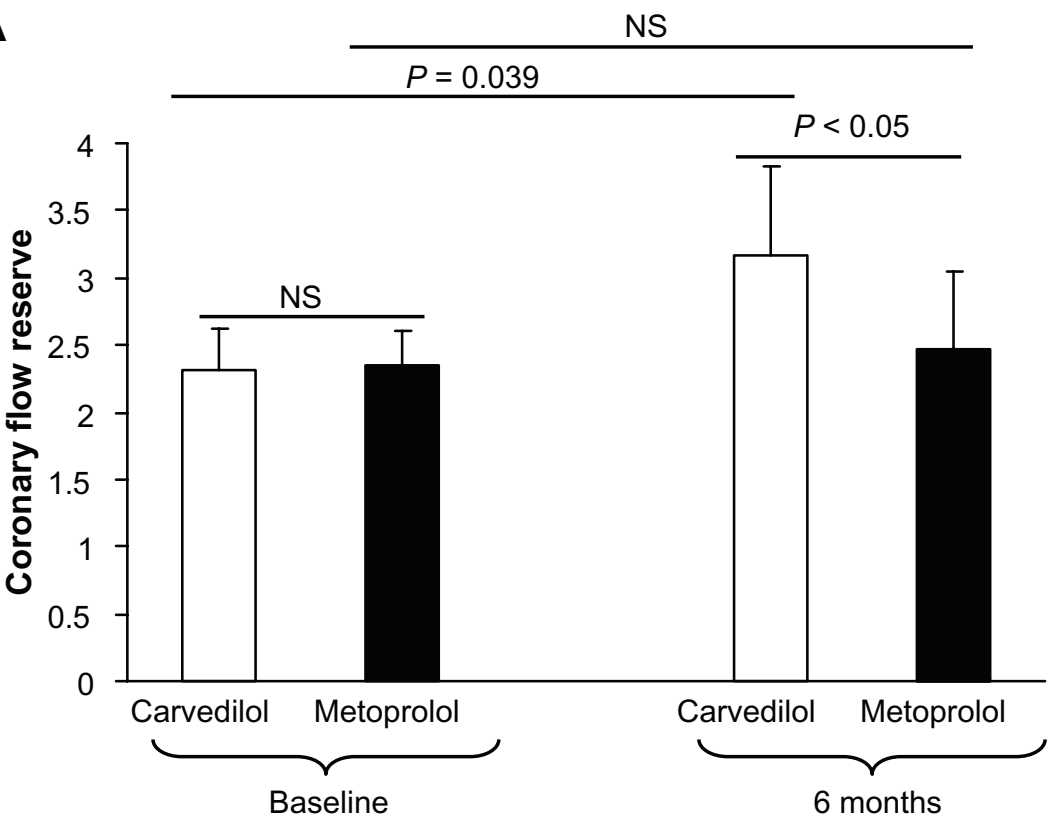

B

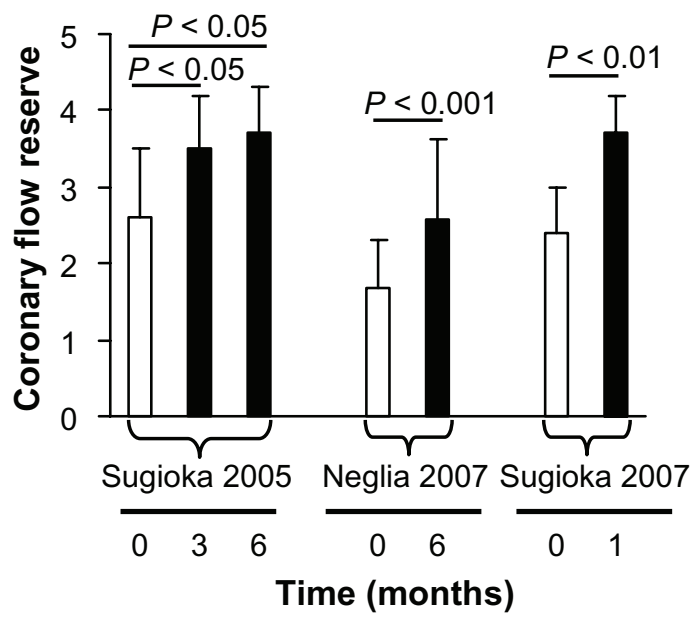

C

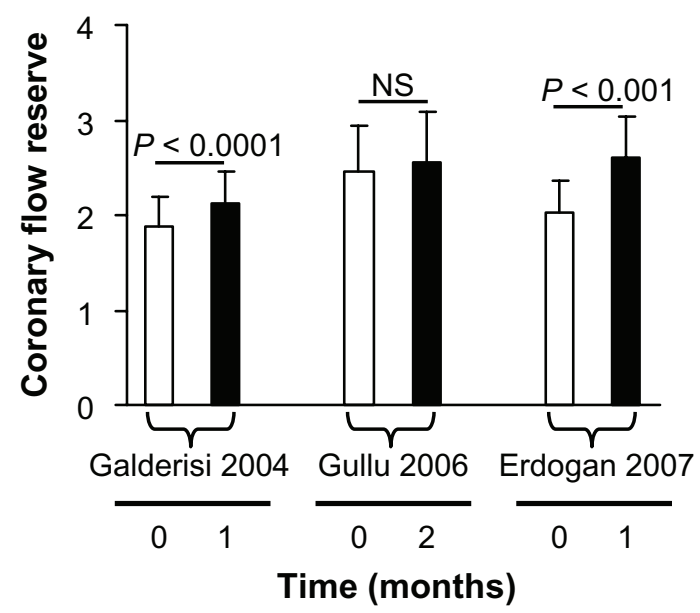

Figure 7 Effect of carvedilol, metoprolol, and nebivolol on coronary flow reserve. (A) Carvedilol was administered at $10 \mathrm{mg}$ twice daily $(\mathrm{n}=28)$ and metoprolol was administered at $50 \mathrm{mg}$ twice daily $(\mathrm{n}=29)$. $P$ values denote statistically significant differences between duration and type of treatment. Adapted from Xiaozhen et al. ${ }^{33}$ (B) Carvedilol was administered at 20-50 mg daily and (C) nebivolol was administered at $5 \mathrm{mg}$ daily. Copyright (c) 2008, ADIS Press. Adapted with permission from Galderisi M, D'Errico A. Beta-blockers and coronary flow reserve: the importance of a vasodilatory action. Drugs. 2008;68(5):579-590.34

Notes: Open bars represent baseline and filled bars represent the treatment time points. Significant differences from baseline are shown. Data are presented as the mean \pm standard deviation.

Society of Cardiology guidelines recommend $\beta$-blockers (as well as other antihypertensive agents) in hypertensive patients after myocardial infarction. ${ }^{1-3}$ The CAPRICORN (Carvedilol Post-Infarct Survival Control in Left Ventricular Dysfunction) trial was specifically designed to examine the benefits afforded by carvedilol in patients with left ventricular systolic dysfunction following acute myocardial infarction. ${ }^{35}$ Although the primary endpoint of this trial failed to reach statistical significance (all-cause mortality or cardiovascular hospitalization), all-cause mortality alone was significantly lower in the carvedilol group than in the placebo group (116 [12\%] versus 151 [15\%]; 95\% confidence interval: $0 \cdot 77[0 \cdot 60-0 \cdot 98], P=0.03)$ and confirmed data from other studies. Based on findings from this trial, the guidelines now indicate carvedilol in this patient group. A recent Norwegian trial compared the antioxidative effects of carvedilol and 
atenolol in 232 patients with acute myocardial infarction. ${ }^{90}$ The findings of this study showed that carvedilol had a more pronounced antioxidative effect than atenolol in post-acute myocardial infarction patients. Together, these studies show that carvedilol is effective and superior to other $\beta$-blockers in the treatment of patients following acute myocardial infarction.

\section{Regression of atherosclerosis}

Carvedilol is known to have many effects which are directly linked to prevention of atherosclerosis. Carotid internalmedial thickness (CIMT) has been shown to be directly associated with changes in morning BP. Therefore, carotid atherosclerosis may be prevented by control of morning BP. In a randomized controlled trial performed in 128 hypertensive patients, treatment with carvedilol for 12 months was shown to decrease morning BP significantly (Figure 8). ${ }^{91}$ Furthermore, in this study, it was observed that CIMT regression occurred in $49 \%$ of patients treated with carvedilol compared with only $18 \%$ of patients treated with metoprolol $(P<0.01) .{ }^{91}$

Matrix metalloproteinase (MMP) is also critical for atherosclerosis formation after vascular injury, and carvedilol, a pharmacological antioxidant, is able to inhibit the expression of MMP-2 and MMP-9 both in vivo and in vitro. This points towards a potential clinical indication for carvedilol

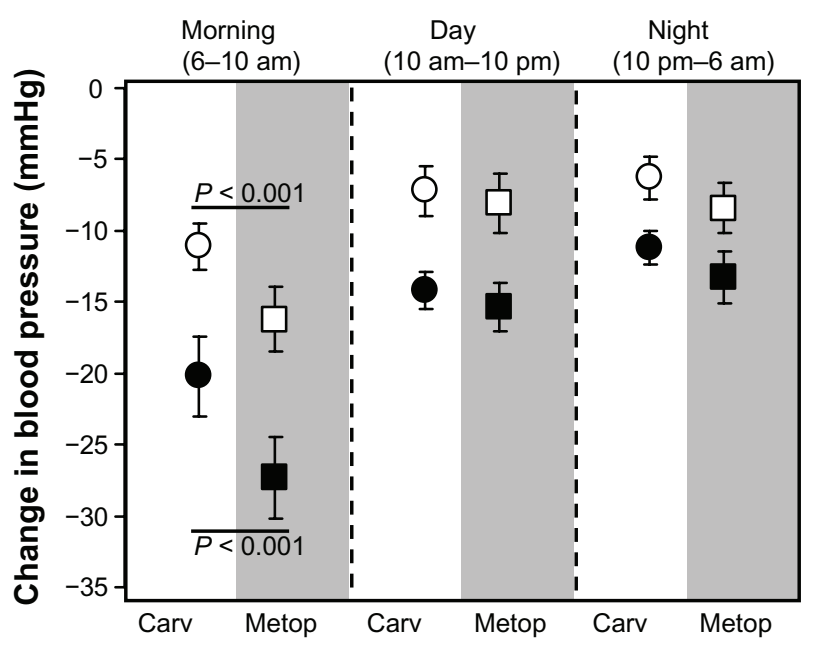

Figure 8 Control of morning blood pressure in newly diagnosed hypertensive patients. The effects of carvedilol 12.5-20 mg and metoprolol 10-20 mg on both systolic (filled dots) and diastolic blood pressure (open dots) were compared over a 24-hour period. Reprinted by permission from Macmillan Publishers Ltd: American Journal of Hypertension. Marfella R, Siniscalchi M, Nappo F, et al. Regression of carotid atherosclerosis by control of morning blood pressure peak in newly diagnosed hypertensive patients. Am J Hypertens. 2005; 18(3):308-318. Copyright 2005.91

Notes: Data are presented as the mean \pm standard deviation. $P$ values represent statistically significant differences between carvedilol and metoprolol groups. Abbreviations: Carv, carvedilol; Metop, metoprolol. in the prevention of atherosclerosis. ${ }^{92}$ Antioxidant and antiinflammatory actions and an ability to decrease the rate of apoptosis of smooth muscle cells are additional features of carvedilol which, collectively, are able to stabilize atherosclerotic plaques. ${ }^{45,93}$ An early sign of atherogenesis is endothelial adhesiveness to human mononuclear cells, induced by tumor necrosis factor-alpha, which has been shown to be reduced by carvedilol by inhibiting production of intracellular reactive oxygen species, activation of transcription factors, and increasing expression of vascular cell adhesion protein-1 and E-selectin, suggesting its potential role in clinical atherosclerosis. ${ }^{94}$ Although accumulating evidence suggests a clinically relevant antiatherogenic role for carvedilol, clinical trials with well defined endpoints are needed to confirm these preliminary findings.

\section{Kidney disease}

Current opinion favors the use of $\beta$-blockers in patients with chronic kidney disease. ${ }^{95}$ In fact, a recent meta-analysis of eight studies $(n=5972)$ showed that $\beta$-blocker therapy improved all-cause mortality in patients with chronic kidney disease and chronic systolic heart failure, reinforcing the use of these agents in this group. ${ }^{96}$ With regard to carvedilol, there is also evidence indicating that this agent exerts renoprotective effects. Earlier studies showed beneficial effects on renal hemodynamics, including decreased renal vascular resistance, in patients with heart failure, despite decreasing systemic BP. ${ }^{97}$ Carvedilol has also been shown to decrease both systolic and diastolic BP without decreasing renal blood flow or glomerular filtration rate, while reducing renal vascular resistance. ${ }^{98}$ Few studies have examined the effects of carvedilol on renal function or clinical outcomes in patients with heart failure and renal dysfunction. However, in one comparative study, metoprolol was observed to decrease estimated glomerular filtration rate significantly, but this did not change in those who received carvedilol. ${ }^{99} \mathrm{~A}$ metaanalysis performed on the CAPRICORN and COPERNICUS (Carvedilol Prospective Randomized Cumulative Survival) trials including 4217 patients ${ }^{35,100}$ suggests that the benefits of carvedilol therapy in patients with left ventricular systolic dysfunction with or without symptoms of heart failure are consistent even in the presence of mild to moderate chronic kidney disease. ${ }^{101}$ Actually, in individuals without chronic kidney disease, the use of carvedilol in the long-term has been shown to improve symptoms of heart failure, increase left ventricular ejection fraction, mitigate neurohormonal activation and peripheral vasoconstriction, and decrease sympathetic overactivity, as well as decrease salt and water 
retention. ${ }^{102,103}$ In contrast with traditional $\beta$-blockers, several trials have demonstrated a beneficial effect of carvedilol on kidney function in terms of increased renal blood flow and a reduction in microalbuminuria..$^{37,38,104,105}$ In addition, among patients with normal urine albumin excretion at baseline in the GEMINI trial, fewer treated with carvedilol progressed to microalbuminuria than those treated with metoprolol $(6.4 \%$ versus $10.3 \%$, respectively). ${ }^{36}$ It is tempting to speculate that carvedilol may vasodilate efferent arterioles, but definitive evidence is not yet available to confirm this. Overall, these findings support a beneficial role for carvedilol on renal function. To assess these renoprotective effects fully, randomized controlled trials with well defined endpoints are needed in patients with nephropathy.

\section{Additional pleiotropic effects}

In addition to the recognized BP-lowering and favorable metabolic effects of carvedilol in a broad range of hypertensive patients, recent preclinical and clinical studies indicate that carvedilol exerts other pleiotropic effects. Although it is recognized that carvedilol is effective in the treatment of patients following acute myocardial infarction, ${ }^{35}$ few studies have compared the additive effects of carvedilol and reninangiotensin system inhibitors. A clinical study retrospectively investigated 251 patients with acute myocardial infarction treated with angiotensin-converting enzyme inhibitors or angiotensin II receptor blockers and divided them into two groups, ie, those treated without $\beta$-blockers $(n=80)$ and those treated with $\beta$-blockers ( $\beta$-blocker group, $n=171$; carvedilol or bisoprolol, $\mathrm{n}=80) .{ }^{106}$ After one year of follow-up, it was found that both survival and cardiac event-free rates in the $\beta$-blocker group were significantly higher than in the group not treated with $\beta$-blockers. Although the percent change in BP did not significantly differ between the two groups, levels of brain natriuretic peptide, MMP-2, and MMP-9, and left ventricular ejection fraction improved significantly in the $\beta$-blocker group. Furthermore, treatment with carvedilol achieved more favorable outcomes than bisoprolol. This study demonstrates that $\beta$-blocker therapy combined with a renin-angiotensin system inhibitor is more effective than treatment with a renin-angiotensin system inhibitor alone in patients with acute myocardial infarction.

Carvedilol has also been shown to inhibit neointimal hyperplasia in patients with coronary artery disease. The effects of carvedilol-loaded stents compared with bare metal stents on clinical outcomes at 2 years was examined in patients with coronary artery disease. ${ }^{107}$ Patients receiving carvedilol-coated stents had an increased luminal area and reduced neointimal thickening compared with patients receiving bare metal stents. These findings demonstrate that carvedilol-loaded stents can inhibit neointimal hyperplasia without increased risk of cardiac death, myocardial infarction, or stent thrombosis at 2-year follow-up.

\section{Tolerability}

$\beta$-blockers are traditionally associated with side effects including depression, fatigue, sexual dysfunction, and cold extremities. ${ }^{108}$ However, evidence is available from several studies indicating that carvedilol has a good tolerability profile. For example, carvedilol therapy was observed to be safe in patients with Duchenne's or Becker's muscular dystrophy, in addition to producing a modest improvement in systolic and diastolic function. ${ }^{109}$ Results from the SATELLITE survey demonstrated that initiation and uptitration of carvedilol in ambulatory care patients with chronic heart failure was feasible and safe. ${ }^{110}$ In this survey, the efficacy and tolerability of carvedilol were at least as good as in the clinical trials, while amelioration of patient well being was significant despite suboptimal dosing. In pediatric patients, carvedilol also appears to be well tolerated. Pediatric patients with chronic heart failure who were not responding to standard therapy benefited from treatment with oral carvedilol, although, because of increased elimination of carvedilol, an age-appropriate optimized carvedilol dosing strategy was used. ${ }^{111,112}$ The safety and efficacy of carvedilol has also been examined in very elderly diabetic patients with heart failure. However, beta-blockers are usually prescribed with caution in these patients because of their perceived unfavorable effects on glucose metabolism, regardless of evidence of their effectiveness and safety in middle-aged diabetic patients. In a recent study of elderly diabetic patients, no worsening of fasting glucose, $\mathrm{HbA}_{1 \mathrm{c}}$ or creatinine levels, or increased incidence of deaths and hospitalizations was observed in elderly diabetics treated with carvedilol. ${ }^{113}$

Furthermore, carvedilol appears to be well tolerated in elderly patients with chronic heart failure, although the very elderly ( $>80$ years) tolerate carvedilol less well than their younger counterparts (70-79 years). Regardless, carvedilol was tolerated in more than $76 \%$ of elderly patients with chronic heart failure at a dose higher than the starting dose. Therefore, the elderly with chronic heart failure should not be denied treatment with carvedilol due to concerns regarding tolerability. ${ }^{114}$ Other studies which have investigated the tolerability of carvedilol in the elderly all conclude that this drug can be administered safely in this age group. ${ }^{115-119}$ Overall, these studies indicate that carvedilol has an excellent 
tolerability profile across a wide range of patient types, thus improving the potential for compliance.

\section{Conclusion}

This report provides compelling evidence for the use of carvedilol as an antihypertensive agent in a wide range of hypertensive population types. Current JNC-7 guidelines recommend use of $\beta$-blockers such as carvedilol for initial treatment of patients with stage 1 hypertension and compelling indications, eg, previous myocardial infarction, ischemic heart disease, heart failure, diabetes, or high risk of coronary artery disease. ${ }^{1} \beta$-blockers are also recommended for initial treatment of patients with stage 1 hypertension without compelling indications and in patients with stage 2 hypertension who require a combination of drugs to achieve BP control. $^{1,120}$

Carvedilol, a vasodilating noncardioselective $\beta$-blocker, allows the opportunity to use a cardioprotective agent without the concerning hemodynamic and metabolic effects associated with traditional $\beta$-blocker therapy. In contrast with classical $\beta$-blockers, carvedilol maintains cardiac output, has a reduced effect on heart rate, and decreases BP mainly by decreasing vascular resistance. Studies comparing carvedilol with conventional $\beta$-blockers have shown that carvedilol has greater benefit in terms of BP-lowering effects whether administered as monotherapy or combined with a diuretic or renin-angiotensin system inhibitor, in addition to improving glycemic control, insulin sensitivity, and lipid metabolism, suggesting that it could be used in subjects with metabolic syndrome or diabetes. Furthermore, the evidence shows that carvedilol can improve LVH and coronary flow reserve, in addition to reducing progression of atherosclerosis and neointimal hyperplasia in patients with coronary artery disease. Carvedilol is also currently indicated in the post-myocardial infarction setting. These distinct multifaceted hemodynamic and metabolic features specific to carvedilol could result in potential beneficial effects in other likely concomitant diseases, such as renal disease and peripheral vascular disease. To assess these further effects fully, randomized controlled trials with well defined endpoints in specific patient populations with underlying hypertension are now required.

\section{Disclosure}

CGE received fees for manuscript preparation on behalf of Primula Multimedia SRL. GL received fees for critical revision of the manuscript. This study was funded by Roche SpA, Italy.

\section{References}

1. Chobanian AV, Bakris GL, Black HR, et al. The seventh report of the joint national committee on Prevention, Detection, Evaluation, and Treatment of High Blood pressure: the JNC 7 report. JAMA. 2003;289(19):2560-2572.

2. Mancia G, De Backer G, Dominiczak A, et al. 2007 ESH-ESC Practice guidelines for the management of arterial hypertension: ESH-ESC Task Force on the Management of Arterial Hypertension. J Hypertens. 2007;25(9):1751-1762.

3. Mancia G, Laurent S, Agabiti-Rosei E, et al. Reappraisal of European guidelines on hypertension management: a European Society of Hypertension Task Force document. J Hypertens. 2009;27(11): 2121-2158.

4. Wolf-Maier K, Cooper RS, Kramer H, et al. Hypertension treatment and control in five European countries, Canada, and the United States. Hypertension. 2004;43(1):10-17.

5. Sarafidis PA, Bakris GL. State of hypertension management in the United States: confluence of risk factors and the prevalence of resistant hypertension. J Clin Hypertens (Greenwich). 2008;10(2):130-139.

6. Volpe M, Tocci G, Trimarco B, et al. Blood pressure control in Italy: results of recent surveys on hypertension. $J$ Hypertens. 2007;25(7): 1491-1498.

7. Sarafidis PA, Bakris GL. Antihypertensive treatment with betablockers and the spectrum of glycaemic control. QJM. 2006;99(7):431-436.

8. Frishman WH. A historical perspective on the development of betaadrenergic blockers. J Clin Hypertens. 2007;9(4 Suppl 3):19-27.

9. Messerli FH, Grossman E. Beta-blockers in hypertension: is carvedilol different? Am J Cardiol. 2004;93 Suppl:7B-12B.

10. Black HR, Sica DA. A modern perspective on beta-blocker use in hypertension: clinical trials and their influence on clinical practice. J Clin Hypertens (Greenwich). 2007;9(4 Suppl 3):10-18.

11. Che Q, Schreiber MJ Jr, Rafey MA. Beta-blockers for hypertension: are they going out of style? Cleve Clin J Med. 2009;76(9):533-542.

12. De Caterina AR, Leone AM. The role of beta-blockers as first-line therapy in hypertension. Curr Atheroscler Rep. 2011;13(2):147-153.

13. Messerli FH, Grossman E, Goldbourt U. Are beta-blockers efficacious as first-line therapy for hypertension in the elderly? A systematic review. JAMA. 1998;279(23):1903-1907.

14. Dahlöf B, Devereux RB, Kjeldsen SE, et al; for the LIFE Study Group. Cardiovascular morbidity and mortality in the Losartan Intervention For Endpoint Reduction in Hypertension study (LIFE): a randomised trial against atenolol. Lancet. 2002;359(9311):995-1003.

15. Carlberg B, Samuelsson O, Lindholm LH. Atenolol in hypertension: is it a wise choice? Lancet. 2004;364(9446):1684-1689.

16. Lindholm LH, Carlberg B, Samuelsson O. Should beta blockers remain first choice in the treatment of primary hypertension? A meta-analysis. Lancet. 2005;366(9496): 1545-1553.

17. Dahlöf B, Severs PS, Poulter NR, et al. Prevention of cardiovascular events with an antihypertensive regimen of amlodipine adding perindopril as required versus atenolol adding bendroflumethiazide, in the Anglo-Scandinavian Cardiac Outcomes Trial-Blood Pressure Lowering arm (ASCOT-BPLA): a multicentre randomized controlled trial. Lancet. 2005;366(9489):895-906.

18. Bangalore S, Parkar S, Grossman E, Messerli FH. A meta-analysis of 94,492 patients with hypertension treated with beta blockers to determine the risk of new-onset diabetes mellitus. Am J Cardiol. 2007;100(8):1254-1262.

19. Wiysonge CS, Bradley H, Mayosi BM, et al. Beta-blockers for hypertension. Cochrane Database Syst Rev. 2007;24(1):CD002003.

20. Williams B, Poulter NR, Brown MJ, et al. Guidelines for management of hypertension: report of the fourth working party of the British Hypertension Society, 2004-BHS IV. J Hum Hypertens. 2004;18(3): 139-185.

21. National Institute for Health and Clinical Excellence. Hypertension: Management of Hypertension in Adults in Primary Care: Pharmacological Update. NICE Clinical Guideline 34. London, UK: National Institute for Health and Clinical Excellence; 2006. 
22. Ritchie LD, Campbell NC, Murchie P. New NICE guidelines for hypertension. Br Med J. 2011;343:d5644.

23. Neutel JM, Smith DH, Ram CV, et al. Application of ambulatory blood pressure monitoring in differentiating between antihypertensive agents. Am J Med. 1993;94(2):181-187.

24. Ali Raza J, Movahed A. Use of cardiovascular medications in the elderly. Int J Cardiol. 2002;85(2-3):203-215.

25. Moser M. Clinical experience with carvedilol. J Hum Hypertens. 1993; 7 Suppl 1:S16-S20.

26. Verma U, Bano G, Mohan Lal B, Sharma KP, Sharm R. Antihypertensive efficacy of carvedilol and amlodipine in patients of mild to moderate hypertension - a comparative study. JK Science. 2004;6(4):193-196.

27. Fonseca VA. Effects of beta-blockers on glucose and lipid metabolism. Curr Med Res Opin. 2010;26(3):615-629.

28. McTavish D, Campoli-Richards D, Sorkin EM. Carvedilol. A review of its pharmacodynamic and pharmacokinetic properties, and therapeutic efficacy. Drugs. 1993;45(2):232-258.

29. Dickstein K, Cohen-Solal A, Filippatos G, et al. ESC guidelines for the diagnosis and treatment of acute and chronic heart failure 2008: the Task Force for the diagnosis and treatment of acute and chronic heart failure 2008 of the European Society of Cardiology. Developed in collaboration with the Heart Failure Association of the ESC (HFA) and endorsed by the European Society of Intensive Care Medicine (ESICM). Eur J Heart Fail. 2008;10(10):933-989.

30. Erdoğan O, Ertem B, Altun A. Comparison of antihypertensive efficacy of carvedilol and nebivolol in mild-to-moderate primary hypertension: a randomized trial. Anadolu Kardiyol Derg. 2011;11(4):310-313. Turkish.

31. Widmann L, van der Does R, Hörrmann M, Machwirth M. Safety and antihypertensive efficacy of carvedilol and atenolol alone and in combination with hydrochlorothiazide. Eur J Clin Pharmacol. 1990; 38 Suppl 2:S143-S146.

32. Tedesco MA, Natale F, Calabrò R. Effects of monotherapy and combination therapy on blood pressure control and target organ damage: a randomized prospective intervention study in a large population of hypertensive patients. J Clin Hypertens (Greenwich). 2006;8(9):634-641.

33. Xiaozhen H, Yun Z, Mei Z, Yu S. Effect of carvedilol on coronary flow reserve in patients with hypertensive left-ventricular hypertrophy. Blood Press. 2010;19(1):40-47.

34. Galderisi M, D'Errico A. Beta-blockers and coronary flow reserve: the importance of a vasodilatory action. Drugs. 2008;68(5):579-590.

35. Dargie H, Colucci WS, Ford I, et al. Effect of carvedilol on outcome after myocardial infarction in patients with left-ventricular dysfunction: the CAPRICORN randomised trial. Lancet. 2001;357(9266): $1385-1390$

36. Bakris GL, Fonseca V, Katholi RE, et al; GEMINI Investigators. Metabolic effects of carvedilol vs metoprolol in patients with type 2 diabetes mellitus and hypertension: a randomized controlled trial. JAMA. 2004;292(18):2227-2236.

37. Dupont AG. Carvedilol and the kidney. Clin Investig. 1992;70 Suppl 1: S127-S131.

38. Marchi F, Ciriello G. Efficacy of carvedilol in mild to moderate essential hypertension and effects on microalbuminuria: a multicenter, randomized, open-label, controlled study versus atenolol. Adv Ther. 1995;12(4):212-221.

39. Toda N. Vasodilating beta-adrenoceptor blockers as cardiovascular therapeutics. Pharmacol Ther. 2003;100(3):215-234.

40. Stafylas PC, Sarafidis PA. Carvedilol in hypertension treatment. Vasc Health Risk Manag. 2008;4(1):23-30.

41. Frishman WH, Henderson LS, Lukas MA. Controlled-release carvedilol in the management of systemic hypertension and myocardial dysfunction. Vasc Health Risk Manag. 2008;4(6):1387-1400.

42. Pedersen ME, Cockcroft JR. The vasodilatory beta-blockers. Curr Hypertens Rep. 2007;9(4):269-277.

43. Frishman WH. Carvedilol. N Engl J Med. 1998;339(24):1759-1765.
44. Kveiborg B, Hermann TS, Major-Pedersen A, et al. Metoprolol compared with carvedilol deteriorates insulin-stimulated endothelial function in patients with type 2 diabetes - a randomized study. Cardiovasc Diabetol. 2010;9:21.

45. Dandona P, Ghanim H, Brooks DP. Antioxidant activity of carvedilol in cardiovascular disease. J Hypertens. 2007;25(4):731-741.

46. Calò LA, Semplicini A, Davis PA. Antioxidant and antiinflammatory effect of carvedilol in mononuclear cells of hypertensive patients. Am J Med. 2005;118(2):201-202.

47. Meyer-Sabellek W, Schulte KL, Distler A, Gotzen R. Circadian antihypertensive profile of carvedilol (BM 14190). J Cardiovasc Pharmacol. 1987;10 Suppl 11:S119-S123.

48. Lund-Johansen P, Omvik P, Nordrehaug JE, White W. Carvedilol in hypertension: effects on hemodynamics and 24-hour blood pressure. J Cardiovasc Pharmacol. 1992;19 Suppl 1:S27-S34.

49. van der Does R, Widmann L, Uberbacher HJ, Hörrmann M, Machwirth M, Stienen U. Efficacy and safety of carvedilol in comparison with atenolol in hypertensive patients pretreated with hydrochlorothiazide. Eur J Clin Pharmacol. 1990;38 Suppl 2:S147-S152.

50. Hall S, Prescott RI, Hallman RJ, et al. A comparative study of carvedilol, slow-release nifedipine, and atenolol in the management of essential hypertension. J Cardiovasc Pharmacol. 1991;8 Suppl:S35-S38.

51. Moser M, Frishman W. Results of therapy with carvedilol, a beta-blocker vasodilator with antioxidant properties, in hypertensive patients. Am J Hypertens. 1998;11(1 Pt 2):15S-22S.

52. Dupont AG, Schoors DF, Venuti RP. The safety of adding carvedilol to hypertensive patients inadequately treated with diuretics. Eur J Clin Pharmacol. 1990;38 Suppl 2:S153-S157.

53. Ogihara T, Yoshinaga K, Kamahara Y, et al. Clinical efficacy of carvedilol in severe hypertension. J Cardiovasc Pharmacol. 1991;18 Suppl 4: S69-S72.

54. Polónia J, Barbosa L, Silva JA, Bertoquini S. Different patterns of peripheral versus central blood pressure in hypertensive patients treated with $\beta$-blockers either with or without vasodilator properties or with angiotensin receptor blockers. Blood Press Monit. 2010;15(5):235-239.

55. Aronow WS. Current role of beta-blockers in the treatment of hypertension. Expert Opin Pharmacother. 2010;11(16):2599-2607.

56. Kasiske BL, Ma JZ, Kalil RS, et al. Effects of antihypertensive therapy on serum lipids. Ann Intern Med. 1995;122(2):133-141.

57. Brook RD. Mechanism of differential effects of antihypertensive agents on serum lipids. Curr Hypertens Rep. 2000;2(4):370-377.

58. Maitland-van der Zee AH, Klungel OH, Kloosterman JM, et al. The association between antihypertensive drug therapies and plasma lipid levels in the general population. J Hum Hypertens. 2001;15(10):701-705.

59. Giugliano D, Acampora R, Marfella R, et al. Metabolic and cardiovascular effects of carvedilol and atenolol in non-insulin-dependent diabetes mellitus and hypertension. A randomized, controlled trial. Ann Intern Med. 1997:126(12):955-959.

60. Messerli FH, Bell DS, Fonseca V, et al; GEMINI Investigators. Body weight changes with beta-blocker use: results from GEMINI. Am J Med. 2007;120(7):610-615.

61. Fonarow GC, Deedwania P, Fonseca V, et al. Differential effects of extended-release carvedilol and extended-release metoprolol on lipid profiles in patients with hypertension: results of the ExtendedRelease Carvedilol Lipid Trial. J Am Soc Hypertens. 2009;3(3): 210-220.

62. Sharp RP, Sirajuddin R, Sharief IM. Impact of carvedilol on the serum lipid profile. Ann Pharmacother. 2008;42(4):564-571.

63. Jacob S, Rett K, Wicklmayr M, et al. Differential effect of chronic treatment with two beta-blocking agents on insulin sensitivity: the carvedilol-metoprolol study. J Hypertens. 1996;14(4):489-494.

64. Haenni A, Lithell H. Treatment with a beta-blocker with beta 2-agonism improves glucose and lipid metabolism in essential hypertension. Metabolism. 1994;43(4):455-461. 
65. Malminiemi K. Association between serum lipids, glucose tolerance, and insulin sensitivity during 12 months of celiprolol treatment. Cardiovasc Drugs Ther. 1995;9(2):295-304.

66. Poole-Wilson PA, Swedberg K, Cleland JG, et al; Carvedilol or Metoprolol European Trial Investigators. Comparison of carvedilol and metoprolol on clinical outcomes in patients with chronic heart failure in the Carvedilol or Metoprolol European Trial (COMET): randomised controlled trial. Lancet. 2003;362(9377):7-13.

67. Wright JT Jr, Bakris GL, Bell DS, et al. Lowering blood pressure with beta-blockers in combination with other renin-angiotensin system blockers in patients with hypertension and type 2 diabetes: results from the GEMINI Trial. J Clin Hypertens (Greenwich). 2007;9(11): 842-849.

68. Carella AM, Antonucci G, Conte M, et al. Antihypertensive treatment with beta-blockers in the metabolic syndrome: a review. Curr Diabetes Rev. 2010;6(4):215-221.

69. Uzunlulu M, Oguz A, Yorulmaz E. The effect of carvedilol on metabolic parameters in patients with metabolic syndrome. Int Heart J. 2006;47(3):421-430.

70. Haider AW, Larson MG, Benjamin EJ, Levy D. Increased left ventricular mass and hypertrophy are associated with increased risk for sudden death. J Am Coll Cardiol. 1998;32(5):1454-1459.

71. Cruickshank JM, Lewis J, Moore V, Dodd C. Reversibility of left ventricular hypertrophy by differing types of antihypertensive therapy. J Hum Hypertens. 1992;6(2):85-90.

72. Dahlof B, Pennert K, Hansson L. Reversal of left ventricular hypertrophy in hypertensive patients: a meta-analysis of 109 treatment studies. Am J Hypertens. 1992;5(2):95-110.

73. Eichstaedt H, Danne O, Schroeder RJ, Kreuz D. Left ventricular hypertrophy regression during antihypertensive treatment. Clin Investig. 1992;70 Suppl 1:S79-S86.

74. Verza M, Ammendola S, Cambardella A, et al. Regression of left ventricular hypertrophy in hypertensive elderly patients with carvedilol. Arch Gerontol Geriatr. 1996;22 Suppl 1:143-147.

75. Tual L, Morel OE, Favret F, et al. Carvedilol inhibits right ventricular hypertrophy induced by chronic hypobaric hypoxia. Pflugers Arch. 2006;452(4):371-379.

76. Khattar RS, Senior R, Soman P, van der Does R, Lahiri A. Regression of left ventricular remodeling in chronic heart failure: comparative and combined effects of captopril and carvedilol. Am Heart J. 2001;142(4):704-713.

77. Nemes A, Neu K, Forster T, Kovacs Z, Csanady M. Coronary flow velocity reserve is diminished in hypertensive left ventricular hypertrophy. Kardiol Pol. 2005;62(1):1-5. Polish.

78. Sugioka K, Hozumi T, Takemoto Y, et al. Early recovery of impaired coronary flow reserve by carvedilol therapy in patients with idiopathic dilated cardiomyopathy: a serial transthoracic Doppler echocardiographic study. J Am Coll Cardiol. 2005;45(2):318-319.

79. Neglia D, De Maria R, Masi S, et al. Effects of long-term treatment with carvedilol on myocardial blood flow in idiopathic dilated cardiomyopathy. Heart. 2007;93(7):808-813.

80. Sugioka K, Hozumi T, Takemoto Y, et al. Relation of early improvement in coronary flow reserve to late recovery of left ventricular function after beta-blocker therapy in patients with idiopathic dilated cardiomyopathy. Am Heart J. 2007;153(6):1080.e1-e6.

81. Galderisi M, Cicala S, D’Errico A, de Divitiis O, de Simone G. Nebivolol improves coronary flow reserve in hypertensive patients without coronary heart disease. J Hypertens. 2004;22(11):2201-2208.

82. Gullu H, Erdogan D, Caliskan M, et al. Different effects of atenolol and nebivolol on coronary flow reserve. Heart. 2006;92(11):1690-1691.

83. Erdogan D, Gullu H, Caliskan M, et al. Nebivolol improves coronary flow reserve in patients with idiopathic dilated cardiomyopathy. Heart. 2007;93(3):319-324.

84. Yusuf S, Peto R, Lewis J, et al. Beta blockade during and after myocardial infarction: an overview of the randomized trials. Prog Cardiovasc Dis. 1985;27(5):335-371.
85. Beta-Blocker Heart Attack Trial Research Group (BHAT). A randomized trial of propranolol in patients with acute myocardial infarction. I. Mortality results. JAMA. 1982;247(12):1707-1714.

86. Herlitz J, Karlson BW, Hjalmarson A. Ten year mortality in relation to original size of myocardial infarct: results from the Gothenburg metoprolol study. Br Heart J. 1994;71(3):238-241.

87. [No authors listed]. Timolol-induced reduction in mortality and reinfarction in patients surviving acute myocardial infarction. $N$ Engl $J$ Med. 1981;304(14):801-807.

88. Smith SC Jr, Allen J, Blair SN, et al. ACC/AHA guidelines for secondary prevention for patients with coronary and other atherosclerotic vascular disease: 2006 update: endorsed by the National Heart, Lung, and Blood Institute. Circulation. 2006;113(19):2363-2372.

89. Rosendorff C, Black HR, Cannon CP, et al. Treatment of hypertension in the prevention and management of ischemic heart disease: a scientific statement from the American Heart Association Council for High Blood Pressure Research and the Councils on Clinical Cardiology and Epidemiology and Prevention. Circulation. 2007;115(21):2761-2788.

90. Jonsson G, Abdelnoor M, Seljeflot I, et al. The antioxidative effects of long-term treatment are more pronounced for carvedilol than for atenolol in post-myocardial infarction patients. $J$ Cardiovasc Pharmacol. 2007;49(1):27-32.

91. Marfella R, Siniscalchi M, Nappo F, et al. Regression of carotid atherosclerosis by control of morning blood pressure peak in newly diagnosed hypertensive patients. Am J Hypertens. 2005;18(3): 308-318.

92. Wu TC, Chen YH, Leu HB, et al. Carvedilol, a pharmacological antioxidant, inhibits neointimal matrix metalloproteinase-2 and -9 in experimental atherosclerosis. Free Radic Biol Med. 2007;43(11): 1508-1522.

93. Guan YY, Ye BH, Lu HH, et al. Study of carvedilol on plaque stability in carotid atherosclerotic rabbits transfected by p53 gene. Zhonghua Xin Xue Guan Bing Za Zhi. 2007;35(1):63-68. Chinese.

94. Chen JW, Lin FY, Chen YH, et al. Carvedilol inhibits tumor necrosis factor-alpha-induced endothelial transcription factor activation, adhesion molecule expression, and adhesiveness to human mononuclear cells. Arterioscler Thromb Vasc Biol. 2004;24(11): 2075-2081.

95. Kalaitzidis R, Bakris G. Should nephrologists use beta-blockers? A perspective. Nephrol Dial Transplant. 2009;24(3):701-702.

96. Badve SV, Roberts MA, Hawley CM, et al. Effects of beta-adrenergic antagonists in patients with chronic kidney disease: a systematic review and meta-analysis. J Am Coll Cardiol. 2011;58(11):1152-1161.

97. Abraham WT, Tsvetkova T, Lowes BD, et al. Carvedilol improves renal hemodynamics in patients with chronic heart failure. $J$ Card Fail. 1998;98 Suppl 1:378-379.

98. Tomita K, Marumo F. Effect of long-term carvedilol therapy on renal function in essential hypertension. J Cardiovasc Pharmacol. 1992; 19 Suppl 1:S97-S101.

99. Ito H, Nagatomo Y, Kohno T, et al. Differential effects of carvedilol and metoprolol on renal function in patients with heart failure. Circ J. 2010;74(8):1578-1583.

100. Packer M, Fowler MB, Roecker EB, et al; Carvedilol Prospective Randomized Cumulative Survival (COPERNICUS) Study Group. Effect of carvedilol on the morbidity of patients with severe chronic heart failure: results of the carvedilol prospective randomized cumulative survival (COPERNICUS) study. Circulation. 2002;106(17) 2194-2199.

101. Wali RK, Iyengar M, Beck GJ, et al. Efficacy and safety of carvedilol in treatment of heart failure with chronic kidney disease: a meta-analysis of randomized trials. Circ Heart Fail. 2011;4(1):18-26.

102. Hillege HL, Girbes AR, de Kam PJ, et al. Renal function, neurohormonal activation, and survival in patients with chronic heart failure. Circulation. 2000;102(2):203-210 
103. Madsen BK, Keller N, Christiansen E, Christensen NJ. Prognostic value of plasma catecholamines, plasma renin activity, and plasma atrial natriuretic peptide at rest and during exercise in congestive heart failure: comparison with clinical evaluation, ejection fraction, and exercise capacity. J Card Fail. 1995;1(3):207-216.

104. Agrawal B, Wolf K, Berger A, Luft FC. Effect of antihypertensive treatment on qualitative estimates of microalbuminuria. J Hum Hypertens. 1996;10(8):551-555.

105. Fassbinder W, Quarder O, Waltz A. Treatment with carvedilol is associated with a significant reduction in microalbuminuria: a multicentre randomised study. Int J Clin Pract. 1999;53(7):519-522.

106. Konishi M, Haraguchi G, Yoshikawa S, et al. Additive effects of $\beta$-blockers on renin-angiotensin system inhibitors for patients after acute myocardial infarction treated with primary coronary revascularization. Circ J. 2011;75(8):1982-1991.

107. Kim HK, Hong YJ, Jeong MH, et al. Two-year clinical outcome after carvedilol-loaded stent implantation in patients with coronary artery disease. Korean J Intern Med. 2011;26(1):41-46.

108. Chakraborty S, Shukla D, Mishra B, Singh S. Clinical updates on carvedilol: a first choice beta-blocker in the treatment of cardiovascular diseases. Expert Opin Drug Metab Toxicol. 2010;6(2):237-250.

109. Rhodes J, Margossian R, Darras BT, et al. Safety and efficacy of carvedilol therapy for patients with dilated cardiomyopathy secondary to muscular dystrophy. Pediatr Cardiol. 2008;29(2):343-351.

110. Lainscak M, Moullet C, Schön N, Tendera M. Treatment of chronic heart failure with carvedilol in daily practice: the SATELLITE survey experience. Int J Cardiol. 2007;122(2):149-155.

111. Läer S, Mir TS, Behn F, et al. Carvedilol therapy in pediatric patients with congestive heart failure: a study investigating clinical and pharmacokinetic parameters. Am Heart J. 2002;143(5):916-922.
112. Albers S, Meibohm B, Mir TS, Läer S. Population pharmacokinetics and dose simulation of carvedilol in paediatric patients with congestive heart failure. Br J Clin Pharmacol. 2008;65(4):511-522.

113. Del Sindaco D, Pulignano G, Cioffi G, et al. Safety and efficacy of carvedilol in very elderly diabetic patients with heart failure. J Cardiovasc Med (Hagerstown). 2007;8(9):675-682.

114. Krum H, Hill J, Fruhwald F, et al. Tolerability of beta-blockers in elderly patients with chronic heart failure: the COLA II study. Eur J Heart Fail. 2006;8(3):302-307.

115. Nul D, Zambrano C, Diaz A, et al; Grupo de Estudio de la Sobrevida en la Insuficiencia Cardiaca en Argentina. Impact of a standardized titration protocol with carvedilol in heart failure: safety, tolerability, and efficacy - a report from the GESICA registry. Cardiovasc Drugs Ther. 2005;19(2):125-134.

116. Lawless CE, Tamlyn T, Shah R, et al. Titration of carvedilol in elderly heart failure patients. Am J Geriatr Cardiol. 2005;14(5):230-235.

117. Leonetti Luparini R, Celli V, Piccirillo G, et al. Carvedilol in elderly patients with chronic heart failure, a 12 weeks randomized, placebo controlled open trial. Arch Gerontol Geriatr. 1999;29(3):275-282.

118. Rickli H, Steiner S, Müller K, Hess OM. Betablockers in heart failure: Carvedilol Safety Assessment (CASA 2-trial). Eur J Heart Fail. 2004:6(6):761-768.

119. Opasich C, Boccanelli A, Cafiero M, et al; BRING-UP 2 Investigators. Programme to improve the use of beta-blockers for heart failure in the elderly and in those with severe symptoms: results of the BRING-UP 2 Study. Eur J Heart Fail. 2006;8(6):649-657.

120. Manrique C, Giles TD, Ferdinand KC, Sowers JR. Realities of newer beta-blockers for the management of hypertension. J Clin Hypertens (Greenwich). 2009;11(7):369-375.
Vascular Health and Risk Management

\section{Publish your work in this journal}

Vascular Health and Risk Management is an international, peerreviewed journal of therapeutics and risk management, focusing on concise rapid reporting of clinical studies on the processes involved in the maintenance of vascular health; the monitoring, prevention and treatment of vascular disease and its sequelae; and the involvement of

\section{Dovepress}

metabolic disorders, particularly diabetes. This journal is indexed on PubMed Central and MedLine. The manuscript management system is completely online and includes a very quick and fair peer-review system, which is all easy to use. Visit http://www.dovepress.com/ testimonials.php to read real quotes from published authors. 